\title{
Evaluation of EPS-PCL Nanofibers as a Nanobiocomposite for Artificial Skin Based on Dermal Fibroblast Culture
}

\author{
Sang-Myung Jung, Dae Seung Kim, Jung Hyeon Ju, and Hwa Sung Shin \\ Department of Biological Engineering, Inha University, Incheon 402-751, Republic of Korea \\ Correspondence should be addressed to Hwa Sung Shin; hsshin@inha.ac.kr
}

Received 18 July 2013; Revised 16 October 2013; Accepted 24 October 2013

Academic Editor: Shafiul Chowdhury

Copyright (C) 2013 Sang-Myung Jung et al. This is an open access article distributed under the Creative Commons Attribution License, which permits unrestricted use, distribution, and reproduction in any medium, provided the original work is properly cited.

\begin{abstract}
Several natural bioactive molecules have been used in the development of scaffolds to enhance biocompatibility or biodegradability and macroalgae contain many bioactive compounds that regulate the physiological activities of cells. In this study, extrapolymeric substances (EPS) from brown algae, Undaria pinnatifida, were dispersed in poly- $\varepsilon$-caprolactone (PCL) nanofiber, fabricated by electrospinning technique to mimic natural extracellular matrix (ECM), and tested as a scaffold for the production of artificial skin using rat primary fibroblasts. The level of adhesion, viability, and infiltration of cells on the EPS-PCL nanofibers were then assessed. The primary fibroblasts attached well, had good viability, and infiltrated through the nanofiber mat without cytotoxicity. Additionally, fibroblast on EPS-PCL nanofiber overcame the stress derived from high cell density at limited area. These results indicate that EPS-imbedded nanofiber has the potential to be used as scaffolds to develop artificial skin or as wound-healing nanomedicines to regenerate injured skin.
\end{abstract}

\section{Introduction}

Skin protects the inner organs of an organism from a variety of stresses. Skin is primarily composed of three layers, the epidermis, dermis, and hyperdermis, each of which contains several types of cells. The dermis layer is made almost completely of fibroblasts, which are known to have an effect on keratinocyte proliferation in the epidermis and to be related to some immune responses of skin $[1,2]$. When the skin is damaged at about $80 \mu \mathrm{m}$, the protected dermis layer can be exposed to air, necessitating regeneration to protect inner tissues. Moreover, in cases in which autoregeneration does not work well and serious scars are left, it is necessary for artificial skin to replace the injured skin for further medical treatments $[3,4]$.

Artificial skin can be made from skin cells cultured in/on three-dimensional biomaterials. Artificial skin requires a scaffold that is able to offer an environment that enables cells to grow well to establish a cellular community as well as to control their proliferation. Considering that all natural tissues make their complete functions via incorporation with extracellular matrix (ECM), scaffolds should be equivalent to
ECM and provide cells with sufficient chances to attach to and spread along scaffolds and activate cellular metabolism normally [5].

To mimic ECM, microenvironment for activating cellular metabolism, nanofibrous scaffold has been intensively applied in tissue engineering. Each nanofiber strand supplies cell attachable point such as collagen fibrous strand of in vivo structure. Adhesion of cells is essential procedure to grow and functionalize anchorage-dependent cells. Additionally, this structural similarity helps represent tissue that consists of a mass of cells by 3-dimensional culture [6].

For forming this structure, there have been several developing processes of materialization such as electrospinning, self-assembled nanofiber, and so on. These processes have already been studied in tissue engineering to replace specific parts of body such as bone [7], heart [8], neuronal system [9], and other parts.

Among those processes, electrospinning is a simple and versatile technique to fabricate well-organized nanofibrous structure, and electrospun nanofibers have frequently been used in the fields of medical and tissue engineering. This is because electrospun nanofibers reproduce almost the same 
structure as natural ECM, which has a diameter between 50 and $500 \mathrm{~nm}[10,11]$. Poly- $\varepsilon$-caprolactone (PCL) is a biodegradable and biocompatible synthetic material that is not cytotoxic; therefore, it is useful for fabrication of such nanofibers.

Natural ECM also has several growth factors and cytokines that influence the physiological activities and metabolism of cells. Therefore, scaffolds for tissue engineering are generally fabricated with bioactive components such as natural peptides, proteins, and polysaccharides. Undaria pinnatifida is a brown macroalga, which is known to produce bioactive components including EPS. In particular, fucoidan, a major component of EPS, has been known as one of the antioxidant, anti-inflammatory, and anticoagulant molecules $[12,13]$. In this study, we investigated whether EPS-imbedded scaffold was suitable for skin tissue engineering based on fibroblast infiltration in the scaffold as well as adhesion and viability.

\section{Materials and Methods}

2.1. Isolation of Primary Fibroblasts from Rat Dermis. Primary fibroblasts were isolated from the dermal layer of SD rats aged 1 day (SAMTACO) as previously described [14]. Briefly, the skin tissue was dissected into small pieces and then placed in HBSS media (Gibco, USA) with dispase $(1 \mathrm{mg} / \mathrm{mL})$ (Sigma, USA) for $24 \mathrm{hr}$ at $4^{\circ} \mathrm{C}$, after which the dermal and epidermal layers were separated and the dermis was incubated with collagenase 2 (Sigma, USA) in HBSS media $(1 \mathrm{mg} / \mathrm{mL})$ for $24 \mathrm{hr}$ at $4^{\circ} \mathrm{C}$. After discarding the tissue debris using a cell strainer with a $70 \mu \mathrm{m}$ pore size (BD Falcon, USA), the harvested cells were harvested in culture medium composed of DMEM high glucose culture medium supplemented with 10\% (v/v) FBS (Gibco, USA) and 1\% (v/v) anti-antibiotic (Gibco, USA). Five passaged fibroblasts were then prepared by successive subculture for all experiments.

2.2. EPS Extraction from Marine Algae Brown Seaweed. Undaria pinnatifida was purchased from Incheon, Republic of Korea. The seaweed was washed with tap water and then dried in oven at greater than $50^{\circ} \mathrm{C}$ for 3 days. Dried samples were then ground, after which $40 \mathrm{~g}$ seaweed was suspended in $250 \mathrm{~mL}$ distilled water and autoclaved at $130^{\circ} \mathrm{C}$ for $30 \mathrm{~min}$. Following autoclaving, the hot solution was separated from the residue, which included the cell mass, by centrifugation at $200 \times \mathrm{g}$ followed by filtration through a Whatman number 1 filter. To increase the bioactive substances ratio, we added excess $\mathrm{CaCl}_{2}$ to the filtrate to precipitate the alginate, a major component of filtered extract. The alginate residues were then removed by centrifugation at over $200 \times \mathrm{g}$ for $20 \mathrm{~min}$, after which the supernatant was mixed with three volumes of EtOH and allowed to stand overnight at $4^{\circ} \mathrm{C}$. The precipitant collected by centrifugation at $14,000 \times \mathrm{g}$ was subsequently redissolved in distilled water and dialyzed using SnakeSkin dialysis tubing (10K MWCO; Thermo Scientific, USA) for $48 \mathrm{hr}$ while changing the distilled water every $12 \mathrm{hr}$. Finally, the EPS powder was obtained through lyophilization.
2.3. Viability of Fibroblasts over Dissolved EPS in the Culture Medium. Fibroblasts were seeded in a 96-well plate at a concentration of $1 \times 10^{3}$ cells/well as low cell density and $5 \times 10^{3}$ cells/well as high cell density cultured for one day, after which EPS was dissolved in culture medium and loaded at $1,10,25$, or $50 \mu \mathrm{g} / \mathrm{mL}$. An MTT assay of the cultured cells was then conducted at days 1, 3, and 5. For observing proliferation, at days 3 and 5, BrdU assay was procedure following manufacturer's guide (Roche applied science, USA) at low cell density. Cell confluence was decided by microscopic image, and if cell covered area was over $80 \%$ of total area, it was said to be confluent. The cell covered area was assayed by image J program.

2.4. Fabrication of EPS-PCL Nanofibers Scaffold. Each $15 \%$ $(\mathrm{v} / \mathrm{v})$ PCL and $15 \%(\mathrm{v} / \mathrm{v})$ PCL with $1 \%(\mathrm{v} / \mathrm{v})$ EPS were dissolved in a solvent of tetrahydrofuran (THF, Junsei, Japan) and NN-dimethylformanide (DMF, Junsei, Japan) (7:3). After each solution was mixed well by a stirrer overnight, it was poured into a syringe with an 18 gauge needle, $15 \mathrm{~cm}$ distant from a collector. Then, the solution was ejected at a flow rate of $2 \mathrm{~mL} / \mathrm{hr}$ under the electric filed at $15 \mathrm{kV}$ which is sufficient to fabricate the nanofibers.

2.5. Cytotoxicity and Adhesion of Fibroblasts with the Nanofibers. To measure the cytotoxicity of the nanofibers toward rat primary fibroblasts, PCL and EPS-PCL nanofibers were incubated in culture medium for $24 \mathrm{hr}$, after which the old medium was loaded with precultured fibroblasts and then seeded in a 96-well plate with a final concentration of $3 \times 10^{3}$ cells/well. After incubation at $37^{\circ} \mathrm{C}$ for 1 day, the cells were subjected to an MTT assay. For the adhesion assay, fibroblasts were cultured on nanofibers with a concentration of $3 \times 10^{4}$ cells per fiber sheet. At 2, 8, and $24 \mathrm{hr}$ after cell-seeding, an MTT assay was performed.

2.6. SEM Image of Fibroblasts on the Nanofibers. Fibroblasts of $1 \times 10^{4}$ cells/well were cultured for 5 days in the PCL and EPS-PCL nanofiber mat in a 24 -well plate. To obtain images using SEM (Hitachi S-4300), the cells were washed with PBS and then incubated with $3 \%$ glutaraldehyde for $30 \mathrm{~min}$ at $37^{\circ} \mathrm{C}$, after which the samples were dehydrated with ethanol with serially increasing concentrations of $25,50,75$, 90 , and $100 \%$. Dehydrated samples were then reacted with three drops of HMDS (Sigma, USA) for 3 min and evaporated for $30 \mathrm{~min}$.

\subsection{Imaging of Fibroblasts That Infiltrated the Nanofibers} Scaffold. Fibroblasts were seeded into PCL and EPS-PCL nanofiber mats at $1 \times 10^{4}$ cells per mat and cultured for 5 days. After incubation, the cells were fixed with $4 \%$ paraformaldehyde for $20 \mathrm{~min}$, subjected to H\&E staining, and then washed with PBS. Dehydration was accomplished by serial treatment with 10,20 , and $30 \%$ ethanol/deionized water, after which the samples were frozen with Tissue-Tek O.C.T compound (Sakura Finetek, USA) at $-20^{\circ} \mathrm{C}$. The samples were next cut into sections with a width of $50 \mu \mathrm{m}$. Just as they became partially sticky at room temperature, they were 


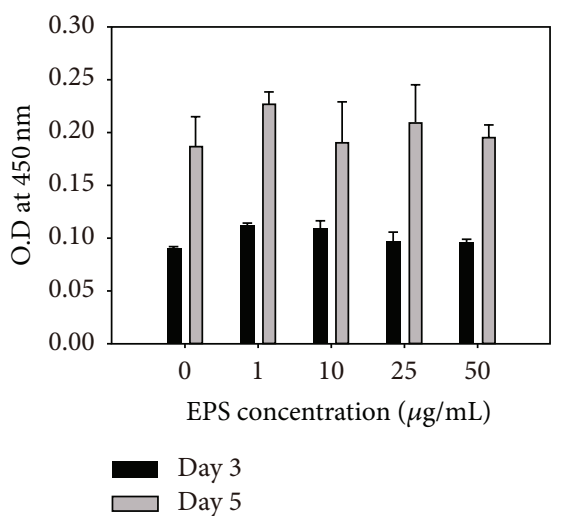

(a)

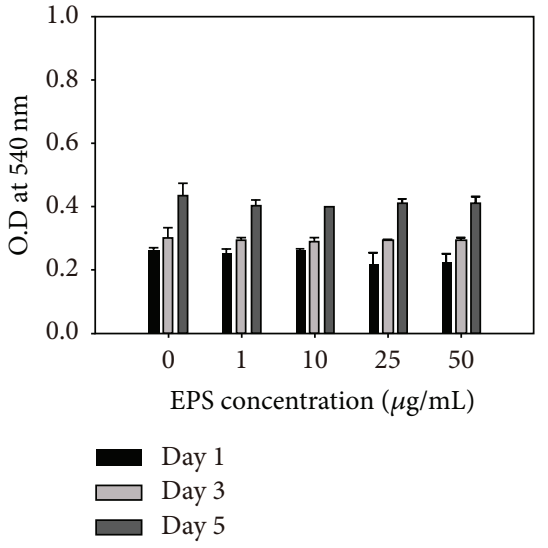

(b)

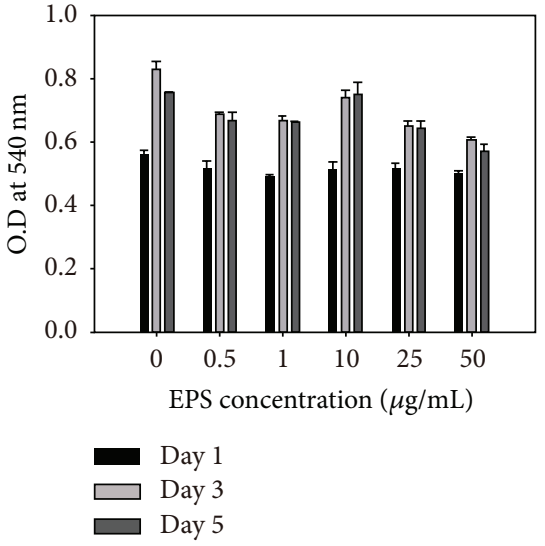

(c)

FIGURE 1: BrdU and MTT assay for cellular activities: (a) proliferation, (b) graph of viability at low cell density inoculum and (c) graph of viability at high cell density inoculum.

attached to slide glasses and then washed twice with PBS at $\mathrm{pH}$ 7.4. Inverted microscopy was used to view the infiltrated fibroblasts through the nanofiber mats.

\section{Results and Discussion}

3.1. Effect of EPS on the Viability of Cells. We investigated the effects of EPS on the activity and proliferation of fibroblasts by MTT assay and BrdU assay, respectively. It is known that soluble MTT is changed into insoluble formazan within the mitochondria of viable cells. As shown in Figure 1(a), EPS extract activated the cellular metabolism, resulting in enhanced fibroblast growth. Cell density imaging was also conducted to determine if changes in EPS concentrations could induce the viability and proliferation of fibroblasts. For comparing nonconfluent and confluent condition, cells were inoculated each concentration. Thereby the samples with low cell density were nonconfluent until day 5 . However samples with high cell density reached confluent condition after 1 day (data not shown). Under nonconfluent conditions (Figure 1(b)), EPS at low concentration under $50 \mu \mathrm{g} / \mathrm{mL}$ had no effect on cellular growth. Conversely, under confluent conditions in which cells would be under negative stresses, the cellular viability decreased (Figure $1(\mathrm{c})$ ). However, cell viability on TCPS was reversed the tendency of cell viability between value of day 3 and that of day 5, significantly. For comparison to TCPS, gaps in the value at day 3 and day 5 were decreased by the addition of EPS until $25 \mu \mathrm{g} / \mathrm{mL}$. At $10 \mu \mathrm{g} / \mathrm{mL}$, the reversed viability between day 3 and day 5 was restored and the cells showed normal growth. These findings indicate that the cells had adapted to the presence of EPS and that EPS protected cells from the stress produced by confluence.

To successfully produce a tissue-like scaffold, cellular metabolism must be increased or at least maintained, even under confluent conditions, because ECM must be continuously produced by the cells to make tissue compact. In this study, cells on nanofibers were found to metabolize less MTT than those on EPS nanofibers (Figure 1(c)). This effect could be an important factor in the development of cell layers to make up tissue.

It is well known that cells usually use oxygen for metabolism but that cells exposed to higher concentrations of $\mathrm{O}_{2}$ show decreased proliferation and cellular metabolism as a result of (reactive oxygen species) ROS $[15,16]$. Dermal fibroblasts are not directly exposed to the air and ROS are more prevalent under normoxia conditions than in vivo [17]. Such produced ROS could damage organelles, leading to cell death [18-20]. However, in our system, EPS acts as an antioxidant owing to the presence of fucoidan. This compound removes free radicals, decreasing the possibility of cell death and damage in organelles [21, 22]. EPS scaffold helps reduce ROS in fibroblasts and maintain cellular metabolism and proliferation similarly to in fibroblasts in vivo, which can facilitate the production of artificial skin.

3.2. Nanofibers Scaffold Fabrication. To confirm whether EPS affects cellular behavior in a structural way, electrospun scaffold was fabricated to give a three-dimensional structure similar to that of tissue in humans. The morphologies of PCL and EPS-PCL nanofibers were then observed by SEM (Figures 2(a) and 2(b)), which revealed that the diameters of the fibers were $1.01 \pm 0.43 \mu \mathrm{m}$ and $1.01 \pm 0.35 \mu \mathrm{m}$, respectively.

3.3. Cytotoxicity of Nanofibers. To determine if toxic substances were released from the nanofibers, each nanofiber was immersed in medium for 1 day. A $t$-test indicated that the growth of fibroblasts did not differ significantly between groups, indicating that the nanofibers were nontoxic toward nanofibers (data not shown).

3.4. Effect of Nanofibers on Cells. As shown in Figure 3(a), the same morphologies were observed in nanofibers from both groups upon SEM. These findings confirmed that the adhesive fibroblasts attached themselves to the nanofibers in a manner similar to ECM. Although the three-dimensional 


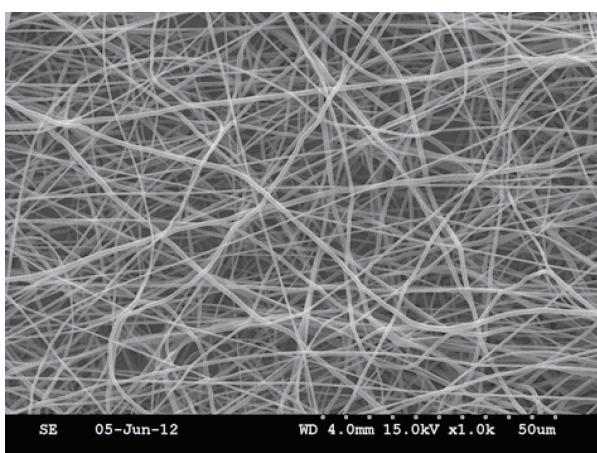

(a)

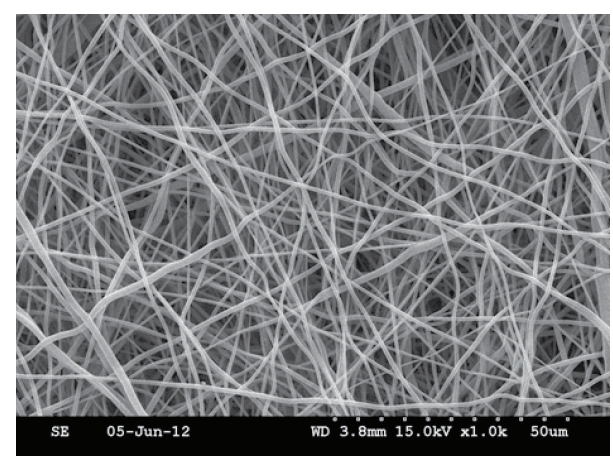

(b)

Figure 2: SEM images of (a) PCL and (b) EPS-PCL nanofibers.

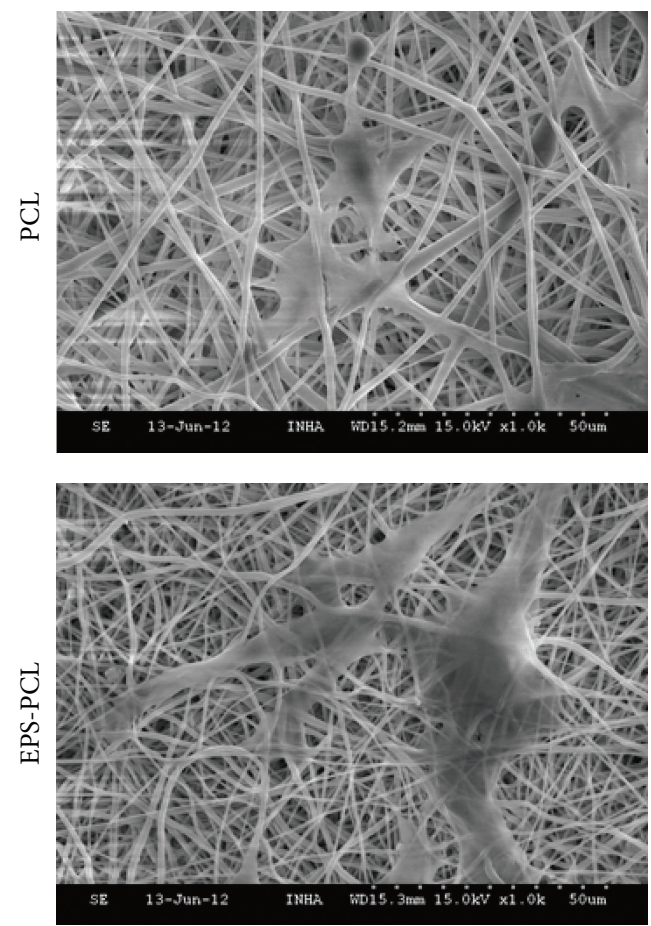

(a)

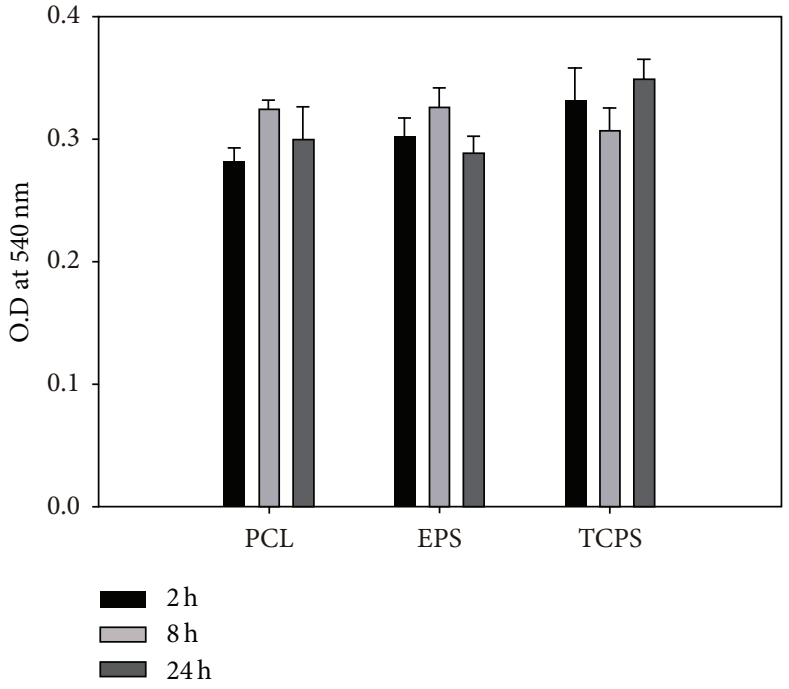

(b)

Figure 3: Analyses of fibroblast adhesion by (a) SEM images and (b) MTT assay.

nanofibers offered less sufficient space to adhere to than that of the two-dimensional scaffold, it seemed likely that, once cells adhered to the nanofibers, they spread along and secreted ECM to keep their surroundings suitable for growth.

Moreover, the cellular adhesion was indirectly studied by MTT assay. To determine how many cells adhered to the nanofibers before cellular division, ELISA was used to measure the OD of formazan-containing media. As seen in Figure 3(b), while the adhesion of fibroblasts in TCPS steadily increased with time, the tendency for EPS-PCL nanofibers toward adhesion was similar to that for the PCL nanofibers at all observed times.

As shown in Figure 3, these findings indicate that the EPS-PCL nanofibers did not exert additional effects on cellular adhesion. Other studies of the effects of nanofibers on cellular adhesion have revealed that nanofiber structure is closely associated with cellular adhesion [23]. Moreover, PCL and EPS-PCL nanofibers were shown to have similar diameter distributions. It can be inferred that the similar adhesion properties were a result of their similar diameter distributions. Until $8 \mathrm{hr}$, the cells were almost completely adhered to each nanofiber, after which some became detached. It is well known that the structure of nanofibers can cause inhibition of cell-cell interaction because the wide surface area decreases the chance for cells to interact and the mechanical confinement by nanofibers induces reversible metabolic inhibition [24]. Based on these facts, it is possible that the MTT values at $24 \mathrm{hr}$ would be decreased. Conversely, cells on TCPS with less surface area had a tendency for cell-cell interaction, for which the cellular metabolism was not reduced. 


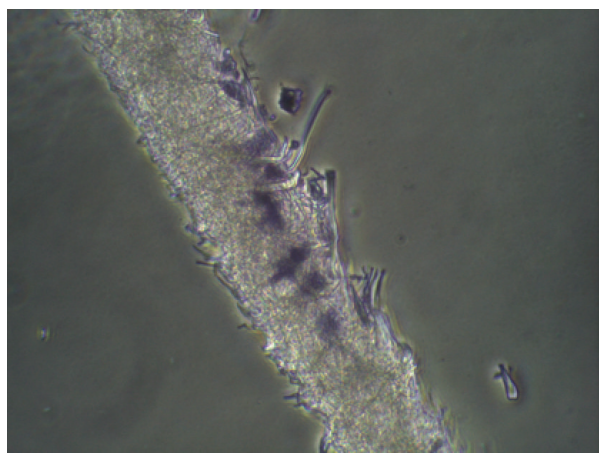

(a)

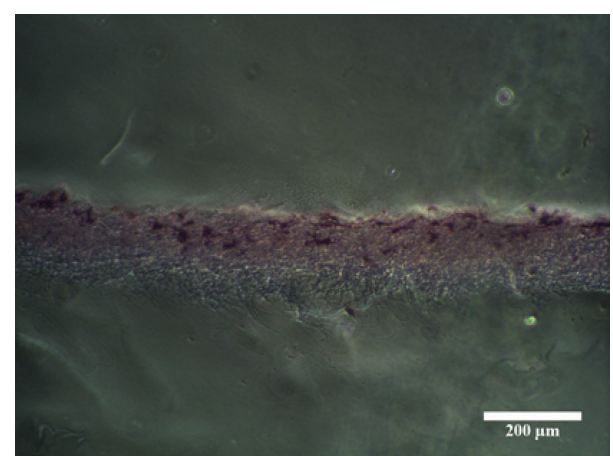

(b)

FIgURE 4: Cross-section assay using H\&E staining. (a) Image of PCL nanofiber mat and (b) EPS-PCL nanofiber mat.

3.5. Infiltration in Nanofibers Scaffolds. Considering that scaffolds offer spaces for cells to grow, it was necessary to investigate the distribution of cells in the newly formed biomaterials after infiltration. To accomplish this, fibroblasts were seeded onto the top of the nanofibers, of which thickness is about $200 \mu \mathrm{m}$ and this is ten times as long as the length of a cell. After the nanofibers were cut, the cross-sections were subjected to H\&E staining to provide greater contrast upon imaging. Figure 4 showed how infiltrated and dispersed cells are into each mat. They infiltrated $100 \mu \mathrm{m}$ down from the place at which they were seeded.

In addition, EPS showed no cytotoxicity during fibroblast infiltration and fibroblast infiltration was not different irrespective of the incorporation of EPS (Figure 4). It is assumed that this is because the nanofiber structure dominates fibroblast infiltration. Indeed, cell infiltration has been reported to be highly affected by nanofiber structure $[25,26]$.

\section{Conclusion}

In order for there to be a cooperative effect between EPS and nanofiber structure, the sensitivity of nanofiber structure to cellular infiltration should first be balanced with that of EPS by controlling the pore size or diameter of the nanofibers. However, such an investigation is beyond the scope of this study. Nevertheless, the results of the present study indicate that the developed nanofibers have the potential for use as a biomaterial in the production of artificial skin by demonstrating that they can enhance fibroblast proliferation without cytotoxicity and support fibroblast infiltration without any critical problems. Fibroblasts could be integrated into EPS nanofibers, indicating that EPS-PCL nanofibers have the potential for use in the manufacture of artificial skin despite showing no obvious difference to nanofibers composed of PCL alone.

\section{Disclosure}

All authors agree to submit the work to "Journal of Nanomaterials." The work has not been published before and is not being submitted to another journal. This paper has been checked by a language editing service prior to submission.

\section{Conflict of Interests}

Because it is required that all authors disclose any potential sources of conflict of interests, all authors also agree that those must be disclosed when directly relevant or indirectly related to the work described in this paper.

\section{Acknowledgments}

This research was a part of the project titled "Technology Development of Marine Industrial Biomaterials," funded by the Ministry of Oceans and Fisheries, Korea.

\section{References}

[1] T.-L. Tuan, L. C. Keller, D. Sun, M. E. Nimni, and D. Cheung, "Dermal fibroblasts activate keratinocyte outgrowth on collagen gels," Journal of Cell Science, vol. 107, no. 8, pp. 2285-2289, 1994.

[2] C. Bouffi, C. Bony, C. Jorgensen, and D. Noël, "Skin fibroblasts are potent suppressors of inflammation in experimental arthritis," Annals of the Rheumatic Diseases, vol. 70, no. 9, pp. A24A25, 2011.

[3] T. Jaksic and J. F. Burke, "The use of "artificial skin" for burns," Annual Review of Medicine, vol. 38, pp. 107-117, 1987.

[4] G. Orlando, K. J. Wood, R. J. Stratta, J. J. Yoo, A. Atala, and S. Soker, "Regenerative medicine and organ transplantation: past, present, and future," Transplantation, vol. 91, no. 12, pp. 13101317, 2011.

[5] K. G. Cornwell, A. Landsman, and K. S. James, "Extracellular matrix biomaterials for soft tissue repair," Clinics in Podiatric Medicine and Surgery, vol. 26, no. 4, pp. 507-523, 2009.

[6] H. Hosseinkhani, Y. Hiraoka, C. H. Li et al., "Engineering three-dimensional collagen-IKVAV matrix to mimic neural microenvironment," ACS Chemical Neuroscience, vol. 4, no. 8, pp. 1229-1235, 2013.

[7] H. Hosseinkhani, M. Hosseinkhani, A. Khademhosseini, and H. Kobayashi, "Bone regeneration through controlled release of bone morphogenetic protein-2 from 3-D tissue engineered nano-scaffold," Journal of Controlled Release, vol. 117, no. 3, pp. 380-386, 2007.

[8] H. Hosseinkhani, M. Hosseinkhani, S. Hattori, R. Matsuoka, and N. Kawaguchi, "Micro and nano-scale in vitro 3D culture 
system for cardiac stem cells," Journal of Biomedical Materials Research A, vol. 94, no. 1, pp. 1-8, 2010.

[9] A. Subramanian, U. M. Krishnan, and S. Sethuraman, "Fabrication of uniaxially aligned 3D electrospun scaffolds for neural regeneration," Biomedical Materials, vol. 6, no. 2, Article ID 025004, 2011.

[10] W.-J. Li, C. T. Laurencin, E. J. Caterson, R. S. Tuan, and F. K. Ko, "Electrospun nanofibrous structure: a novel scaffold for tissue engineering," Journal of Biomedical Materials Research, vol. 60, no. 4, pp. 613-621, 2002.

[11] X. M. Mo, C. Y. Xu, M. Kotaki, and S. Ramakrishna, "Current research on electrospinning of silk fibroin and its blends with natural and synthetic biodegradable polymers," Biomaterials, vol. 25, no. 10, pp. 1883-1890, 2004.

[12] K. Senni, J. Pereira, F. Gueniche et al., "Marine polysaccharides: a source of bioactive molecules for cell therapy and tissue engineering," Marine Drugs, vol. 9, no. 9, pp. 1664-1681, 2011.

[13] K.-J. Kim and B.-Y. Lee, "Fucoidan from the sporophyll of Undaria pinnatifida suppresses adipocyte differentiation by inhibition of inflammation-related cytokines in 3T3-L1 cells," Nutrition Research, vol. 32, no. 6, pp. 439-447, 2012.

[14] L. Rittié and G. J. Fisher, "Isolation and culture of skin fibroblasts," Methods in Molecular Medicine, vol. 117, pp. 83-98, 2005.

[15] R. Djurhuus, A. M. Svardal, and E. Thorsen, "Toxicity of hyperoxia and high pressure on $\mathrm{C} 3 \mathrm{H} / 10 \mathrm{~T} 1 / 2$ cells and effects on cellular glutathione," Undersea and Hyperbaric Medicine, vol. 25, no. 1, pp. 33-41, 1998.

[16] W. Konsavage, L. Zhang, T. Vary, and J. S. Shenberger, "Hyperoxia inhibits protein synthesis and increases eIF2 $\alpha$ phosphorylation in the newborn rat lung," American Journal of Physiology_Lung Cellular and Molecular Physiology, vol. 298, no. 5, pp. L678-L686, 2010.

[17] F. Brugè, E. Venditti, L. Tiano, G. P. Littarru, and E. Damiani, "Reference gene validation for qPCR on normoxia- and hypoxia-cultured human dermal fibroblasts exposed to UVA: is $\beta$-actin a reliable normalizer for photoaging studies?" Journal of Biotechnology, vol. 156, no. 3, pp. 153-162, 2011.

[18] K. C. Kregel and H. J. Zhang, "An integrated view of oxidative stress in aging: basic mechanisms, functional effects, and pathological considerations," American Journal of PhysiologyRegulatory Integrative and Comparative Physiology, vol. 292, no. 1, pp. R18-R36, 2007.

[19] K. F. Ferri and G. Kroemer, "Organelle-specific initiation of cell death pathways," Nature Cell Biology, vol. 3, no. 11, pp. E255E263, 2001.

[20] W.-X. Zong and C. B. Thompson, "Necrotic death as a cell fate," Genes and Development, vol. 20, no. 1, pp. 1-15, 2006.

[21] J. Han, S. Kang, R. Choue et al., "Free radical scavenging effect of Diospyros kaki, Laminaria japonica and Undaria pinnatifida," Fitoterapia, vol. 73, no. 7-8, pp. 710-712, 2002.

[22] N. Nishibori, T. Sagara, T. Hiroi et al., "Protective effect of Undaria pinnatifida sporophyll extract on iron induced cytotoxicity and oxidative stress in PC12 neuronal cells," Phytopharmacology, vol. 2, no. 2, pp. 271-284, 2012.

[23] F. Tian, H. Hosseinkhani, M. Hosseinkhani et al., "Quantitative analysis of cell adhesion on aligned micro- and nanofibers," Journal of Biomedical Materials Research A, vol. 84, no. 2, pp. 291-299, 2008.

[24] N. C. Hunt, R. M. Shelton, and L. M. Grover, "Reversible mitotic and metabolic inhibition following the encapsulation of fibroblasts in alginate hydrogels," Biomaterials, vol. 30, no. 32, pp. 6435-6443, 2009.

[25] B. M. Baker, A. O. Gee, R. B. Metter et al., "The potential to improve cell infiltration in composite fiber-aligned electrospun scaffolds by the selective removal of sacrificial fibers," Biomaterials, vol. 29, no. 15, pp. 2348-2358, 2008.

[26] J. B. Lee, S. I. Jeong, M. S. Bae et al., "Highly porous electrospun nanofibers enhanced by ultrasonication for improved cellular infiltration," Tissue Engineering A, vol. 17, no. 21-22, pp. 26952702, 2011. 

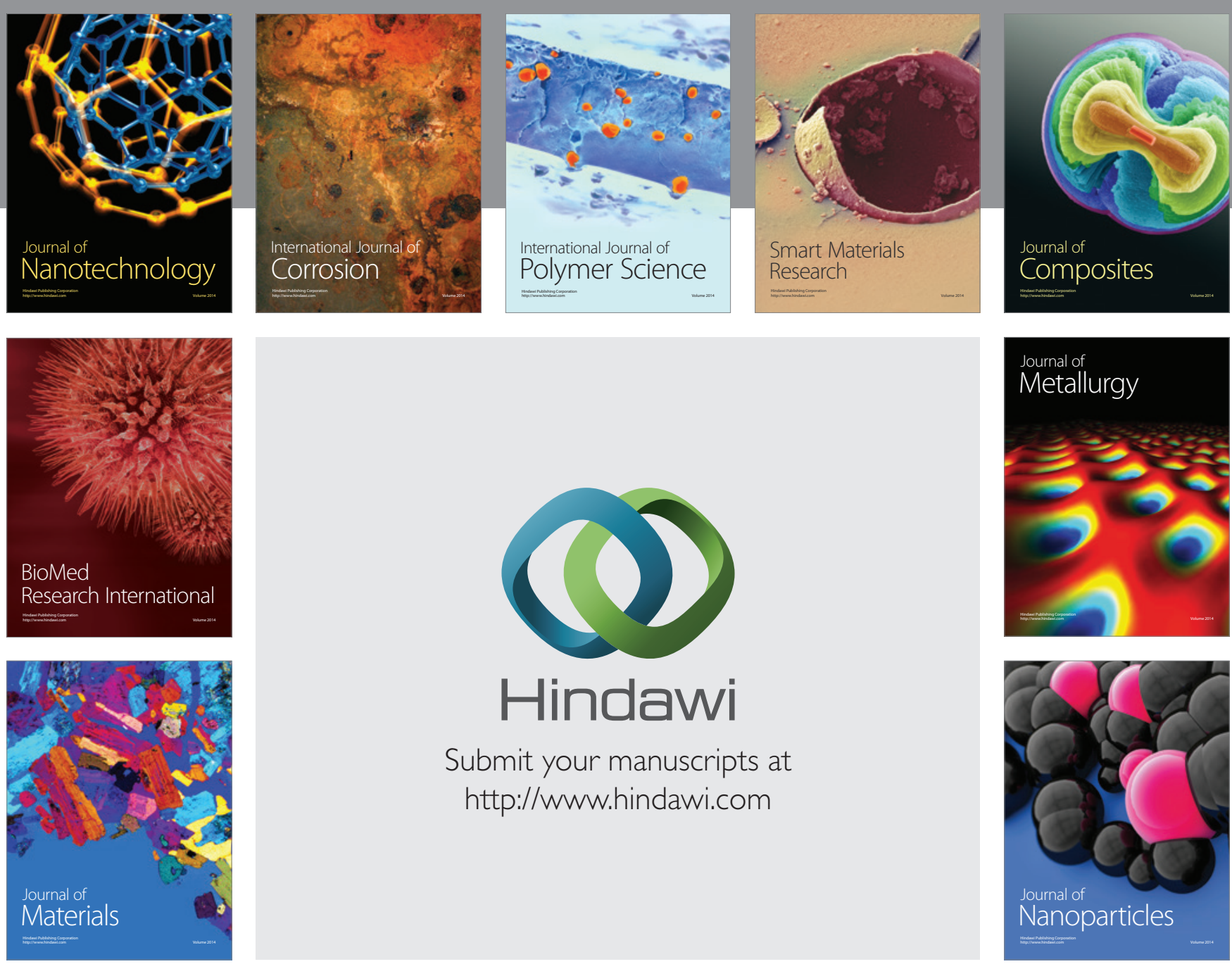

Submit your manuscripts at http://www.hindawi.com
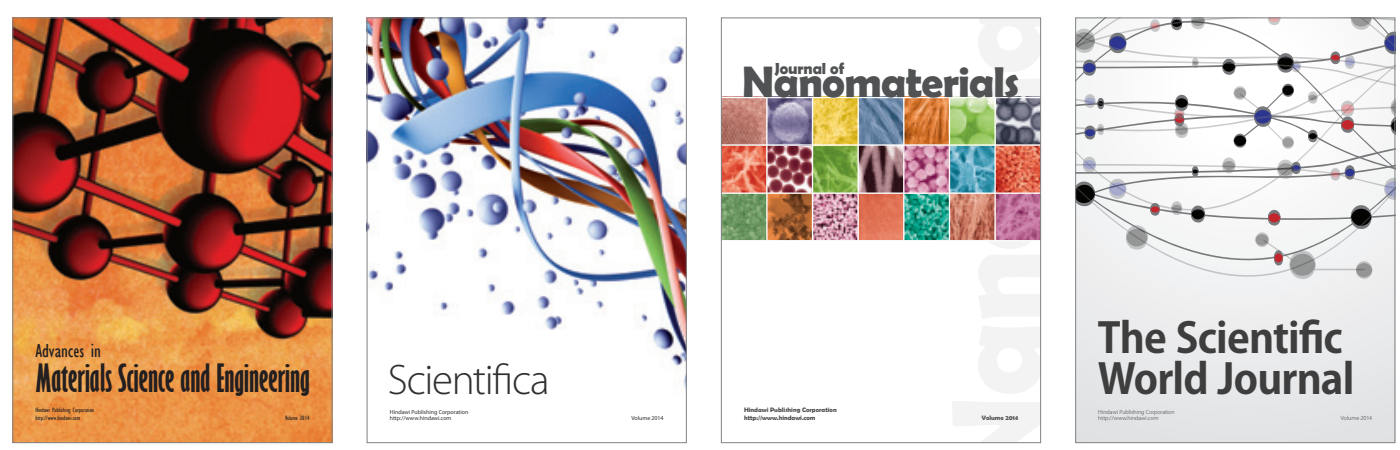

\section{The Scientific World Journal}
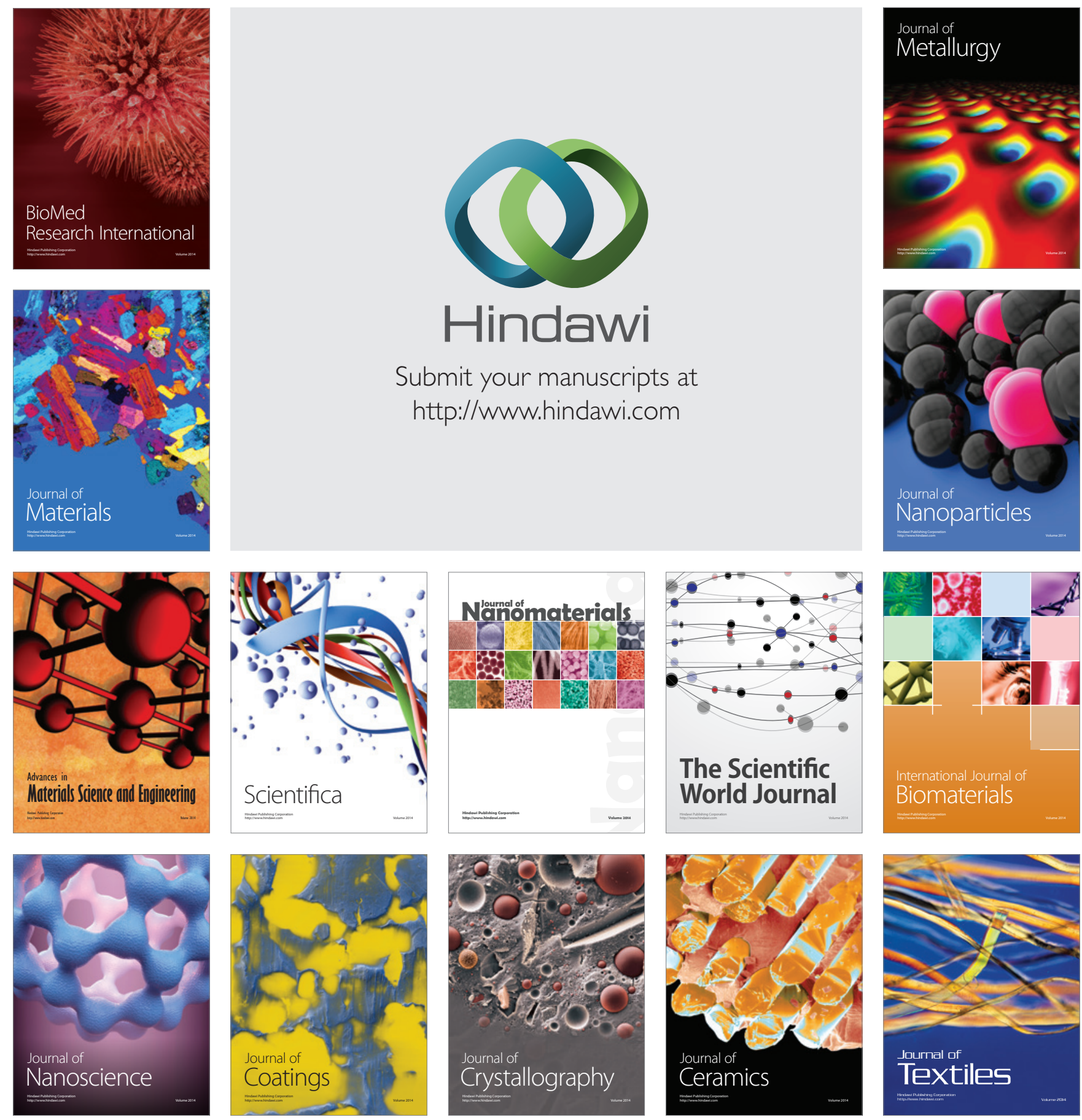